\title{
Relationship Between Arm Span Measurements And Body Height In Bijelo Polje
}

\author{
Marko Knezevic ${ }^{1}$ \\ 'University of Montenegro, Faculty for Sport and Physical Education, Niksic, Montenegro
}

\begin{abstract}
In light of rather sparse recent scientific literature, the purpose of this research study was to examine the body height in both sexes of Montenegrin adults nowadays. Furthermore, the relationship between arm span and body height, which varies in different ethnic and racial groups, was used as an alternative to estimating the body height for some groups of the population. The nature and scope of this study analyses 71 adolescents ( 35 men, aged 17.91+-0.37 and 36 women, aged 17.86+-0.35) from Bijelo Polje. The anthropometric measurements were taken according to the protocol of the International Society for the Advancement of Kinanthropometry (ISAK). Means and standard deviations were obtained. A comparison of means of body heights and arm spans within and between the sexes were carried out using a t-test. The relationships between body height and arm span were determined using simple correlation coefficients and their $95 \%$ confidence interval. A linear regression analysis was then performed to examine the extent to which arm span can reliably predict body height. The results have shown that male from Bijelo Polje are $183.75 \pm 7.49$ centimetres tall and have an arm span of $182.68 \pm 8.31$ centimetres, while female from Bijelo Polje are $169.53 \pm 6.63$ centimetres tall and have an arm span of $165.58 \pm 7.51$ centimetres. Comparing the results with other studies has shown that both sexes of Bijelo Polje are very tall.
\end{abstract}

Key words: Prediction, Standing Height, Stature, Arm Span, Bijelo Polje

\section{Uvod}

Crna Gora je je mala zemlja, koja se nalazi na zapadnom dijelu Balkanskog poluostrva, odnosno na jugoistiku Evrope. Graniči se sa Hrvatskom, Bosnom i Hercegovinom, Srbijom, Kosovom, Albanijom, dok priobalni dio mora, međunarodnim vodama čini granicu sa Italijom. Površina Crne Gore iznosi $13,821 \mathrm{~km}^{2}$. Tokom istorije mnoge velike sile poput Turske, Njemačke, Italije, Austrougarske, ratovali su sa Crnom Gorom, sa ciljem da zauzmu njena teritorijalna područja, za koje su smatrali da, su zbog svog geografskog područja, idealno mjesto za razvoj trgovine i drugih djelatnosti. Od 1918. Crna Gora je bila u zajednici država tadašnje Jugoslavije, koja je vremenom zbog političkog djelovanja mijenjala imena, sve do 21. maja 2006. godine gdje Crna Gora na referendum dobija status nezavisne države. Po popisu iz 2011. godine, Crna Gora ima 620.029 stanovnika. Glavni grad Crne Gore je Podgorica, a prijestonica Cetinje. Po svojoj reljefnoj strukturi
Crna Gora je planinska zemlja, gdje vrhovi dosežu velike visine od kojih su najviši Bobotov Kuk (Durmitor) - 2522m Maja Rozit (Prokletije) - 2522m. U Crnoj Gori se nalazi čak pet nacionalnih parkova (Lovćen, Skadarsko jezero, Biogradska gora, Durmitor i Prokletije), što govori da je posebna pažnja usmjerena na zaštitu prirodne sredine i životinjskog svijeta. Glavna djelatnost je turizam koji je podjednako zastupljen $\mathrm{u}$ primorskim i planinskim krajevima.

Grad Bijelo Polje smješten je na sjeveroistoku Crne Gore uz magistralni put i prugu Beograd-Bar, uokviren s juga planinom Bjelasicom $(2.137 \mathrm{~m})$, a sa sjevera Lisom $(1.509 \mathrm{~m})$, površine $924 \mathrm{~km} 2$ sa 46.051 stanovnika bjelopoljska opština po površini četvrta, a po broju stanovnika treća u državi, predstavlja saobraćajno, trgovačko i kulturno-obrazovno čvorište crnogorskog sjevera. Gradsko jezgro smješteno je na dvijema akumulacionim terasama na visini od $575 \mathrm{~m}$, dok je okolni ruralni prostor ispresijecan rječnim dolinama Ljuboviđe,

Correspondence:

Montenegro M. Knezevic

Gport University of Montenegro, Faculty for Sport and Physical Education, Narodne omladine bb, 81400 Niksic, Montenegro E-Mail:knez_m@hotmail.com 
Lješnice, Bistrice i drugih pritoka Lima. Klima je umjereno kontinentalna. Teritorija Bijelog Polja je kotlinsko - planinska oblast sa veoma povoljnim uslovima za razvoj mnogih grana poljoprivrede i turizma.

Kada se govori o stanovništvu, za Crnogorce možemo reći da su visoki ljudi. Istraživanja koja su sprovedena jos prije 100 godina govore da je prosjek visine muškaraca u Crnoj Gori iznosio $177 \mathrm{~cm}$ (Coon, 1975). Istraživanja na istu temu sprovedena su početkom XX vijeka gdje je prosječna visina kod $\mathrm{Cr}$ nogoraca iznosila $178 \mathrm{~cm}$. Pored ovog, novija istraživanja govore da su muškarci koji žive na predjelu dinarskog dijela Apla, zapravo navisočiji ljudi u Evropi (Pineau, Delamarche i Božinović, 2005). Imajući u vidu geografsko područje Crne Gore, i zastupljenost dinarskih planina na gotovo cijeloj površini, istraživače je navelo da vjeruju da su Crnogorci najvisočija nacija u Evropi. Istraživanje koje je sproveo Coon (1975) ustanovio je da su Crnogorci visočiji od Hercegovaca (175-176cm), Bosanaca (171-174cm), kao i od muškaraca sa prostora Dalmacije $(166-171 \mathrm{~cm})$. Visna tijela je veoma važan pokazatelj u velikom broju istraživanja (Bjelica et al. 2012; Golshan, Amra, \& Hoghoghi, 2003;). Međutim, visinu tijela veoma često nije moguće odrediti već postojećom standardnom procedurom. Razlog tome treba tražiti u određenim posturalnim deformitetima, amputacijama pojedinih segmenata tijela kao i povredama ili oduzetosti ekstremiteta (Quanjer et al. 2014). U ovim okolnostima, visinu tijela potrebno je odrediti pomoću drugih indikatora, kao što su dužina ruku i stopala (Bjelica et al. 2012; Agnihotri, Agnihotri, Jeebun i Googoolye, 2008; Agnihotri, Purwar, Googoolybe, Agnihotri i Jeebun, 2007), visine koljena (Bjelica et al. 2012; Hickson i Frost, 2003), dužine grudne kosti (Bjelica et al. 2012; Menezes et al. 2009; Menezes et al. 2011), dužine kičmenog stuba (Bjelica et al. 2012), sjedeća visina (Bjelica et al. 2012), dužina lopatice (Bjelica et al. 2012; Campobasso, Di-Vella i Introna, 1998), raspona ruku (Bjelica et al. 2012; Hickson i Frost, 2003), širine lobanje (Bjelica et al. 2012; Bidmos, 2006; Bidmos i Asala, 2005) i drugi. Prema tome, svi navedeni antropometrijski indikatori, koji se koriste kao alternativa za procjenu relativne tjelesne visine, veoma su važni u svim slučajevima gore navedenim, a u kojima je tjelesna visina značajna te se ne može izmjeriti standardnom metodom. Takođe, važno je istaći da sve navedeno treba i mora primijeniti u sportskim naukama, budući da je tjelesna visina glavni indikator uspjeha u pojedinim sportskim disciplinama (Mašanović, 2017; Popović, 2017). Značajan je broj istraživanja koja su upućivala na korisnost primjenjivanja različitih tjelesnih parametara $u$ procjenjivanju relativne tjelesne visine (Mašanović, 2017; Popovic, Arifi, \& Bjelica, 2017; Popovic, \& Bjelica, 2017; Popovic, Gardasevic, Masanovic, Arifi, \& Bjelica, 2017), a ispostavilo se da je raspon ruku, upravo pouzdaniji od svih ostalih (Mašanović, 2017).

Osnovni cilj ovog rada bio je da se ispita tjelesna visina kod oba pola adolescenata opštine Bijelo Polje, kao i da se utvrdi da li raspon ruku može biti adekvatna alternativna mjera za utvrdivanje relativne tjelesne visine.

\section{Metod}

U ovom istraživanju učestvovalo je ukupno 71 ispitanik (35 muških i 36 ženskih) iz opštine Bijelo Polje. Starost ispitanika muškog pola iznosi $17.91 \pm 0.37$, odnosno starost osoba ženskog pola iznosi 17.86+-0.35 godina. Raspon u godinama ispitanika bio je od 17 do 19 godina. Ključni kriterijumi za prihvatanje uzorka ispitanika muškog i ženskog pola bili su da: ispitanik dobrovoljno učestvuje u radu i da živi na prostoru opštine Bijelo Polje.

Analiza je izvršena korišćenjem statističkog paketa za društvene nauke (SPSS) verzija 20.0. Srednja vrijednost i standardna devijacija raspona ruku i tjelesne visine, prikazana je za oba pola deskriptivnom statistikom. Za utvrđivanje statistički značajne razlike između oba pola u rasponu ruku i tjelesnoj visini, korišten je $\mathrm{t}$ - test. Odnosi između tjelesne visine i raspona ruku određeni su koeficijentom korelacije sa pouzdanošću od devedeset pet posto intervala. Zatim je izvršena analiza linearne regresije gdje rezultati pokazuju u kojoj mjeri se na osnovu raspona ruku može pouzdano predvidjeti relativna tjelesna visina. Statistička značajnost je postavljena na $\mathrm{p}<0.05$.

\section{Rezultati}

Rezultati antropometrijskih mjera prikazani su u tabeli 1. Srednja vrijednost raspona ruku kod muškaraca iznosi $182.68 \pm 8.31 \mathrm{~cm}$ što je $1.07 \pm 0.82 \mathrm{~cm}$ manje od srednje vrijednosti tjelesne visine i statisticki je značajan $(t=10.545, p<0.000)$, dok je srednja vrijednost raspona ruku za žensku populaciju

Tabela 1. Antropometrijski presjek ispitivanih osoba

\begin{tabular}{ccc}
\hline Ispitanici & $\begin{array}{c}\text { Tjelesna visina } \\
\text { (Srednja vrijednost } \pm \text { SD) }\end{array}$ & $\begin{array}{c}\text { Raspon ruku } \\
\text { (Srednja vrijednost } \pm \text { SD) }\end{array}$ \\
\hline \multirow{2}{*}{ Muški } & $163.0-198.0$ & $160.0-201.5$ \\
& $(183.75 \pm 7.49)$ & $(182.68 \pm 8.31)$ \\
Ženski & $156.0-187.1$ & $154.5-187.1$ \\
& $(169.53 \pm 6.63)$ & $(165.58 \pm 7.51)$ \\
\hline
\end{tabular}

bila $165.58 \pm 7.51 \mathrm{~cm}$ koja je manja u odnosu na tjelesnu visinu za $3.95 \pm 0.88 \mathrm{~cm}$ i statisticki je takođe značajna $(\mathrm{t}=10.085$, $\mathrm{p}<0.000$ ). Razlike u polu između tjelesne visine i raspona ruku su bile takođe statisticki značajne (tjelesna visina: $t=73.467$, $\mathrm{p}<0.000$; raspon ruku: $\mathrm{t}=66.107, \mathrm{p}<0.000)$.
U tabeli 2. prikazan je koeficijent korelacije izmedju varijabli koje su ispitivane. Ono što se vidi u prikazanoj tabeli je da postoji povezanost između tjelesne visine i raspona ruku, da je ta povezanost značajna $(\mathrm{p}<0.000)$ i da je velika u ovome uzorku, bez obzira na pol (muškarci: 0.881; djevojke: 0.866 ).

Tabela 2. Koeficijent korelacije između tjelesne visine i raspona ruku kod ispitivanih osoba

\begin{tabular}{ccc}
\hline Ispitanici & Koeficijent korelacije & p-vrijednost \\
\hline Muški & 0.881 & $<0.000$ \\
Ženski & 0.866 & $<0.000$ \\
\hline
\end{tabular}

Korelacija je značajna na nivou 0.01 
Rezultati linearne regresione analize prikazeni su u tabeli 3. Prije svega ispitana je povezanost godina kao kovarijanse sa varijablama su ispitane i utvrđeno je da godine nijesu značaj- ne i zbog toga su izostavljene iz analize podataka. Dobijene su visoke vrijednosti regresionom analizom (muški pol: 0.881 ; ženski pol: 0.866). Ovo pokazuje da raspon ruku značajno

Tabela 3. Rezultati linearne regresione analize

\begin{tabular}{cccccc}
\hline Ispitanici & $\begin{array}{c}\text { Regresioni } \\
\text { koeficijent }\end{array}$ & $\begin{array}{c}\text { Standardna } \\
\text { greska }\end{array}$ & R-kvadrat (\%) & t-vrijednost & p-vrijednost \\
\hline Muški & 0.881 & 3.59 & 77.7 & 10.545 & 0.000 \\
Ženski & 0.866 & 3.37 & 74.9 & 10.085 & 0.000 \\
\hline
\end{tabular}

predviđa tjelesnu visinu kod ispitivanih uzoraka oba pola sa područja opštine Bijelo Polje, što potvrđuje R-kvadrat (\%) za osobe muškog pola (77.7) i osobe ženskog pola (74.9).
Povezanost između raspona ruku i tjelesne visine je prikazana u skater dijagramu iznad (Diagram 1)

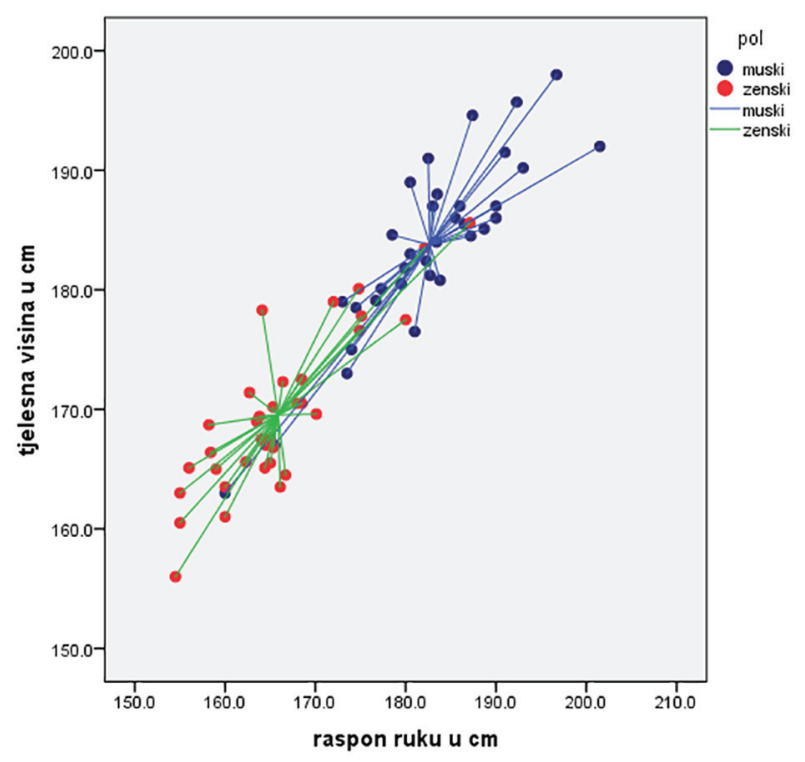

Diagram 1. Skater dijagram i veza između raspona ruku i tjelesne visine kod oba pola

\section{Diskusija}

Istraživanja o visini tijela bila su glavna tema u Evropi, Americi i Japanu još prije 250 godina (Popović, 2017). Neobičnu visinu Crnogoraca nastanjenih na planinskim predjelima dokazali su antropolozi jos prije 100 godina (Bjelica et al., 2012). Za razliku od drugih zemalja zapadnog Balkana, istraživanja sa ovog područja sadrže loše zapise, stoga svako istraživanje novijeg doba je važno za antropološka istraživanja uopšte (Popović, 2017).

Popovic (2017) izvršio je istraživanje sa ciljem da utvrdi nivo tjelesne visine u Crnoj Gori po pojedinim opštinama. Prosječna tjelesna visina iznosila je $183.36 \pm 6.89 \mathrm{~cm}$. Kada je $u$ pitanju opština Bijelo Polje, za muškarce koji su bili podvrgnuti ovom testiranju, može se reći da su veoma visoki, nešto više iznad prosjeka $183.77 \pm 7.25 \mathrm{~cm}$. Znajući da moderni Crnogorci spadaju u rasnu dinarsku klasifikaciju (Bjelica i sar., 2012), autori smatraju da su Crnogorci sa sjevera Crne Gore visočiji od prosječnih stanovnika dinarskog područja, zbog specifične fizičke strukture karakteristične za ljude ovog podneblja.

Kada su u pitanju osobe ženskog pola isti autor je došao do rezultata da ukupan uzorak na nivou države ima prosječnu visinu $169.38 \pm 6.37 \mathrm{~cm}$, a da su ispitanice iz opštine Bijelo Polje su sa prosječnom visinom od $168.90 \pm 6.11 \mathrm{~cm}$. Konačno, kada se uporede rezultati koje je dobio autor ovog istraživanja i rezultate koje je dobio Popović, kada je u pitanju Bijelo Polje, rezultati osoba muškog pola su gotovo isti, dok rezultati osoba ženskog pola sa poručja opštine Bijelo Polje govore da su više za $1 \mathrm{~cm}$ u odnosu na rezultate koje je predstavio Popović.

Rezultati ove studije pokazali su da su osobe muškog pola iz Bijelog Polje sa prosječnom tjelesnom visinom $183.75 \pm 7.49 \mathrm{~cm}$ i rasponom ruku $182.68 \pm 8.31 \mathrm{~cm}$, visočiji od muškaraca južne regije Crne Gore sa prosječnom tjelesnom visinom $182.53 \mathrm{~cm}$ i rasponom ruku $184.55 \mathrm{~cm}$ (Milašinović, Popović, Matić, Gardašević i Bjelica, 2016), od muškaraca sjeverne regije Crne Gore sa visinom tijela $183.29 \mathrm{~cm}$ i rasponom ruku $184.29 \mathrm{~cm}$ (Milašinović, Gardašević i Bjelica, 2017), od centralne regije Crne Gore sa tjelesnom visinom $183.66 \mathrm{~cm}$ i rasponom ruku $184.91 \mathrm{~cm}$ (Vujović, Bubanja, Tanase i Milašinović, 2015), od muškaraca sjeverne regije Kosova sa prosječnom tjelesnom visinom $180.29 \pm 5.72 \mathrm{~cm}$ (Mašanović, Gardašević i Arifi, 2018a), muškaraca centralne regije Kosova sa prosječnom tjelesnom visinom $180.32 \pm 5.88 \mathrm{~cm}$ (Mašanović, Gardašević i Arifi, 2018b), od starijih muškaraca sa Kosova čija je prosječna tjelesna visina $179.52 \pm 5.96 \mathrm{~cm}$, a raspon ruku $181.29 \pm 7.02 \mathrm{~cm}$ (Arifi i sar., 2017), od osoba muškog pola istočne regije Kosova sa prosječnom tjelesnom visinom $178.79 \pm 6.07 \mathrm{~cm}$ (Mašanović, 2018), od starijih osoba sa Kosova sa prosječnom tjelesnom visinom $179.52 \pm 5.96 \mathrm{~cm}$ (Popović i Bjelica, 2017), od starijih muškaraca iz Crne Gore sa rezultatima tjelesne visine $183.21 \pm 7.06 \mathrm{~cm}$ i raspona ruku $185.71 \pm 8.17 \mathrm{~cm}$ (Bjelica et al. 2012), od Makedonaca sa prosječnom visinom $178.10 \pm 6.79 \mathrm{~cm}$ i rasponom ruku $178.78 \pm 7.71 \mathrm{~cm}$ (Popovic, Bjelica, Georgiev, Krivokapic, \& Milasinovic, 2016), od starijih osoba iz Srbije sa prosječnom tjelesnom visinom $181.96 \pm 6.74 \mathrm{~cm}$ i rasponom 
ruku $184.78 \pm 8.41 \mathrm{~cm}$ (Popovic, Bjelica, Molnar, Jaksic, \& Akpinar, 2013).

Kada su u pitanju ispitanice ženskog pola na teritoriji opštine Bijelo Polje, konstatovano je da njihova prosječna tjelesna visina iznosi $169.53 \pm 6.63 \mathrm{~cm}$, što je iznad prosjeka koji važi za žensku populaciju u Crnoj Gori, a iznosi $169.38 \mathrm{~cm}$ (Popović, 2017). Prosječan raspon ruku adolescentkinja opštine Bijelo Polje iznosi $165.58 \pm 7.51 \mathrm{~cm}$. Ako se uporedi prosječna visina adolescentkinja opštine Bijelo Polje sa prosjekom koji važi za svaku od regija Crne Gore rezultati govore da su Bjelopoljke više od prosjeka koji je dobijen za sjevernu regiju i iznosi $168.96 \mathrm{~cm}$, dok je niži rezultat zabilježen kada se govori o prosječnim rasponom ruku adolescentkinja sjeverne regije koji iznosi $167.71 \mathrm{~cm}$ (Milašinović, Gardašević i Bjelica, 2017). Takođe iznad prosjeka su od rezultata koji je dobijen u južnoj regiji, a koji iznosi $168.73 \mathrm{~cm}$, dok je raspon ruku adolescentkinja opštine Bijelo Polje niži od prosječnog raspona ruku osoba ženskog pola sa poručja južne regije koji iznosi $167.23 \mathrm{~cm}(\mathrm{Mi}-$ lašinović, Popović, Jakšić, Vasiljević i Bjelica, 2016). Kada je u pitanju srednja regija, osobe ženskog pola iz Bijelog Polje imaju neznatno veći rezultat kada je u pitanju procjena tjelesne visine srednje regije koji iznosi $169.24 \mathrm{~cm}$, dok je prosječan raspon ruku niži od prosjeka srednje regije koji iznosi $168.03 \mathrm{~cm}$ (Bubanja, Vujović, Tanase, Hadžić i Milašinović, 2015).

Na kraju, bitno je naglasiti da dobijeni rezultati za mušku i žensku populaciju na teritoriji opštine Bijelo Polje govore da su stanovnici ovog podneblja veoma visoki. Ovi rezultati predstavljaju samo potvrdu istrazivanja koja su dokazali Milašinović, Gardašević i Bjelica (2017), a koji govore o tome da su Crnogorci sa sjeverne regije Crne Gore najviši ljudi u Crnoj Gori. Kao krajnji zaključak ovog istraživanja može se navesti da su očekivanja koja su postavljena i ispunjena, odnosno potvrđeno je da je raspon ruku adekvatna alternativna mjerea relativne tjelesne visini kod oba pola adolescenata opštine Bijelo Polje. Takođe potvrđena je činjenica da su muški adolescenti među njavišima, ako ne i najviši u Crnoj Gori, ali prelaze prosjek koji prelazi prosječnu tjelesnu visinu stanovnika Crne Gorea samim tim konkurentni su i na nivou Evrope.

\section{Acknowledgements}

There are no acknowledgements.

\section{Conflict of Interest}

The authors declare that there are no conflict of interest.

Received: 04 May 2018| Accepted: 15 June 2018| Published: 13 July 2018

\section{References}

Arifi, F., Bjelica, D., Sermaxhaj, S., Gardasevic, J., Kezunovic, M., \& Popovic, S. (2017). Stature and its Estimation Utilizing Arm Span Measurements in Kosovan Adults: National Survey. International Journal of Morphology, 35(4), 1161-1167.

Bjelica, D., Popovic, S., Kezunovic, M., Petkovic, J., Jurak, G., \& Grasgruber P. (2012). Body Height and Its Estimation Utilizing Arm Span Measurements in Montenegrin Adults. Anthropological Notebooks, 18(2), 69-83.

Bubanja, M., Vujovic, D., Tanase, G. D., Hadzic, R., \& Milasinovic, R. (2015). Body Height and Its Estimation Utilizing Arm Span Measurements in Female Adolescents from Central Region in Montenegro. Sport Mont, 12(43-45), 277-82.

Gardasevic, J. (2018). Standing Height/Tibia Length Ration in Western-Kosovan Adolescents. Retrieved from SSRN's eLibrary: https://ssrn.com/ abstract $=3138101$

Gardasevic, J. (2018a). Standing Height/Sitting Height Ration in Eastern-Kosovan Adolescents. Retrieved from SSRN's eLibrary: https://ssrn.com/ abstract $=3141566$

Gardasevic, J., Masanovic, B., \& Arifi, F. (2018). Relationship Tibia Length/ Standing Height in Central-Kosovan Adolescents. Retrieved from
SSRN's eLibrary: https://ssrn.com/abstract $=3138122$

Gardasevic, J., Masanovic, B., \& Arifi, F. (2018a). Relationship Tibia Length/ Standing Height in Northern-Kosovan Adolescents. Retrieved from SSRN's eLibrary: https://ssrn.com/abstract=3138112

Gardasevic, J., Masanovic, B., \& Arifi, F. (2018b). Relationship Tibia Length/ Standing Height in Southern-Kosovan Adolescents. Retrieved from SSRN's eLibrary: https://ssrn.com/abstract=3138105

Gardasevic, J., Rasidagic, F., Krivokapic, D., Corluka, M., \& Bjelica, D. (2017). Stature and Its Estimation Utilizing Arm Span Measurements in Male Adolescents from Herzeg-Bosnia Entity in Bosnia and Herzegovina. Montenegrin Journal of Sports Science and Medicine, 6(1), 37-44.

Masanovic, B. (2017). Relationship between arm span measurements and body height in Dinaric Alpes population: A systematic review. Journal of Anthropology of Sport and Physical Education, 1(1), 33-37.

Masanovic, B. (2018). Standing Height and its Estimation Utilizing Arm Spam and Foot Length Measurements in Dinaric Alps Population: A Systematic Review. Sport Mont, 16(2), 1-6.

Masanovic, B. (2018a). Standing Height/Sitting Height Relationhip in Western Region in Kosovo. Retrieved from SSRN's eLibrary: https://ssrn. com/abstract $=3138518$

Masanovic, B. (2018b). Tibia Length and Standing Heigh Relationshipt in Eastern Region of Kosovo. Retrieved from SSRN's eLibrary: https://ssrn. com/abstract $=3143118$

Masanovic, B., Gardasevic, J., \& Arifi, F. (2018a). Relationship between foot length measurements and body height: A prospective regional study among adolescents in eastern region of Kosovo. Sport Mont, 16(1), 9-13. doi: $10.26773 / \mathrm{smj} .180202$

Masanovic, B., Gardasevic, J., \& Arifi, F. (2018b). Relationship between Foot Length Measurements and Body Height: A Prospective Regional Study among Adolescents in Northern Region of Kosovo. Anthropologie-International Journal of Human Diversity and Evolution, in pres, https:// doi.org/10.26720/anthro.18.01.23.1

Masanovic, B., Gardasevic, J., \& Arifi, F. (2018c). Relationship between Foot Length Measurements and Body Height: A Prospective Regional Study among Adolescents in Central Region of Kosovo. Journal of Contemporary Medical Sciences, in press

Masanovic, B., Gardasevic, J., \& Arifi, F. (2018d). Standing Height and its Estimation Utilizing Foot Length Measurements in Adolescents from Southern Region in Kosovo. Sport Mont, 16(2), 101-6.

Masanovic, B., Gardasevic, J., \& Arifi, F. (2018e). Sitting Height/Standing Height Relationship in Southern Region of Kosovo. Retrieved from SSRN's eLibrary: https://ssrn.com/abstract=3138523

Masanovic, B., Gardasevic, J., \& Arifi, F. (2018f). Sitting Height/Standing Height Relations in Central Region of Kosovo. Retrieved from SSRN's eLibrary: https://ssrn.com/abstract=3138525

Masanovic, B., Gardasevic, J., \& Arifi, F. (2018g). Sitting Height/Standing Height Relationship Measurements in Northern Region of Kosovo. Retrieved from SSRN's eLibrary: https://ssrn.com/abstract=3138526

Milašinović, R., Popović, S., Bjelica, D., \& Vasiljević, I. (2016). Body height and its estimation utilizing arm span measurements in female adolescents from northern region in Montenegro. In Book of Abstracts of 4th International Scientific Conference "Exercise and Quality of Life" (39), Novi Sad: Faculty of Sport and Physical Education.

Milasinovic, R., Popovic, S., Jaksic, D., Vasilejvic, I., \& Bjelica, D. (2016b). Stature and its Estimation Utilizing Arm Span Measurements in Feale Adolescents from Southern Region in Montenegro. Sport Mont, 14(3), 15-18.

Milasinovic, R., Popovic, S., Matic, R., Gardasevic, J., \& Bjelica, D. (2016a). Body Height and its Estimation Utilizing Arm Span Measurements in Male Adolescents from Southern Region in Montenegro. Sport Mont, 14(2), 21-23.

Popovic, S. (2016). Body Height and its Estimation Utilizing Arm Span Measurements in Montenegrin Adults: National Survey. In Book of Summaries of 11th FIEP European Congress "Anthropological Aspects of Sport, Physical Education and Recreation" (5-6), Banjaluka: University of Banjaluka, Faculty of Physical Education and Sport.

Popovic, S. (2017). Local Geographical Differences in Adult Body Height in Montenegro. Montenegrin Journal of Sports Science and Medicine, 6(1), $81-87$

Popovic, S., \& Bjelica, D. (2016). Body Height and its Estimation Utilizing Arm Span Measurements in Kosovan Adolescence: National Survey. In Abstract Book of International Eurasian Conference on Sport, Education, and Society (9), Antalya: International Science Culture and Sport Association.

Popovic, S., \& Bjelica, D. (2016). Body Height and its Estimation Utilizing Arm Span Measurements in Kosovan Adolescence: National Survey. In Abstract Book of International Eurasian Conference on Sport, Education, and Society (9), Antalya: International Science Culture and Sport Association. 
Popovic, S., \& Bjelica, D. (2017). Body Height and its Estimation Utilizing Foot Length Measurements in Kosovan Adults: National Survey. In $A b-$ stract Book of the Sport Science Conference AESA 2017 (2), Amol: Faculty of Sport Sciences, Shomal University; Asian Exercise and Sport Science Association.

Popovic, S., Arifi, F., \& Bjelica, D. (2017a). Standing Height and its Estimation Utilizing Foot Length Measurements in Kosovan Adults: National Survey. International Journal of Applied Exercise Physiology, 6(2), 1-7.

Popovic, S., Bjelica, D., Georgiev, G., Krivokapic, D., \& Milasinovic, R. (2016). Body Height and its Estimation Utilizing Arm Span Measurements in Macedonian Adults. Anthropologist, 24(3), 737-745.

Popović, S., Bjelica, D., Milašinović, R., \& Gardašević, J. (2016). Body height and its estimation utilizing arm span measurements in male adolescents from northern region in Montenegro. In Book of Abstracts of 4th International Scientific Conference "Exercise and Quality of Life" (38), Novi Sad: Faculty of Sport and Physical Education.

Popović, S., Bjelica, D., Milašinović, R., Gardašević, J., \& Rašidagić, F. (2016). Body height and its estimation utilizing arm span measurements in male adolescents from Herzeg-Bosnia entity in Bosnia and Herzegovina. In Book of Abstracts of IUAES Inter Congress "World anthropologies and privatization of knowledge: engaging anthropology in public" (148), Dubrovnik: International Union of Anthropological and Ethnological Sciences.

Popovic, S., Bjelica, D., Molnar, S., Jaksic, D., \& Akpinar, S. (2013). Body Height and Its Estimation Utilizing Arm Span Measurements in Serbian Adults. International Journal of Morphology, 31(1), 271-279.

Popović, S., Bjelica, D., Petković, J., Muratović, A. \& Georgiev, G. (2014). Body
Height and Its Estimation Utilizing Arm Span Measurements in Macedonian Adolescents. In Abstract Book of the 7th Conference for Youth Sport (40), Ljubljana: Faculty of Sport, University of Ljubljana.

Popovic, S., Bjelica, D., Tanase, G.D. \& Milasinovic, R. (2015). Body Height and Its Estimation Utilizing Arm Span Measurements in Bosnian and Herzegovinian Adolescents. Montenegrin Journal of Sports Science and Medicine, 4(1), 29-36.

Popovic, S., Gardasevic, J., Masanovic, B., Arifi, F., \& Bjelica, D. (2017b). Standing Height and its Estimation Utilizing Foot Length Measurements in Adolescents from Western Region in Kosovo. Sport Mont, 15(3), 3-7.

Popović, S., Milašinović, R., Jakšić, D., Vasiljević, I., Bjelica, D. (2016). Body height and its estimation utilizing arm span measurements in female adolescents from southern region in Montenegro. In Book of Abstracts of the 13th International Scientific Conference on Transformation Process in Sport "Sport Performance" (30), Podgorica: Montenegrin Sports Academy.

Popović, S., Milašinović, R., Matić, R., Gardašević, J., Bjelica, D. (2016). Body height and its estimation utilizing arm span measurements in male adolescents from southern region in Montenegro. In Book of Abstracts of the 13th International Scientific Conference on Transformation Process in Sport "Sport Performance" (29-30), Podgorica: Montenegrin Sports Academy.

Quanjer, P.H., Capderou, A., Mazocioglu, M.M., Aggarwal, A., Popovic, S. Datta Banik, S., Tayie, F.A.K., Golshan, M., Ip, M.S.M., \& Zelter, M. (2014). All-age relationship between arm span and height in different ethnic groups. European Respiratory Journal, 44(4), 905-912. 